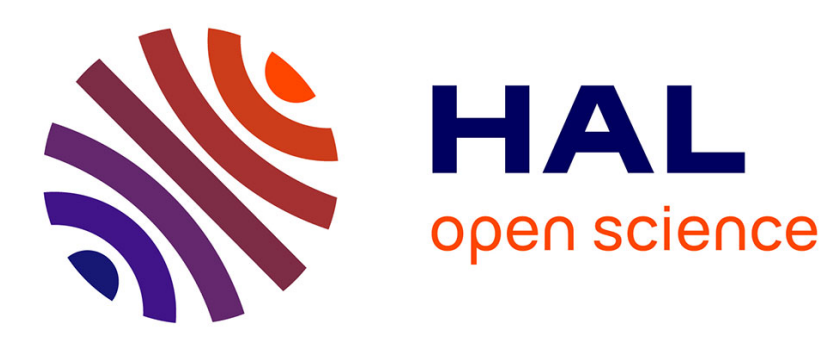

\title{
Experimental characterisation of a plume above rectangular thermal sources. Effect of aspect ratio.
}

\author{
René Devienne, Jean-Raymond Fontaine
}

\section{To cite this version:}

René Devienne, Jean-Raymond Fontaine. Experimental characterisation of a plume above rectangular thermal sources. Effect of aspect ratio.. Building and Environment, 2012, 49 (March 2012), pp.17-24. 10.1016/j.buildenv.2011.09.020 . hal-00752568

\section{HAL Id: hal-00752568 https://hal.science/hal-00752568}

Submitted on 16 Nov 2012

HAL is a multi-disciplinary open access archive for the deposit and dissemination of scientific research documents, whether they are published or not. The documents may come from teaching and research institutions in France or abroad, or from public or private research centers.
L'archive ouverte pluridisciplinaire HAL, est destinée au dépôt et à la diffusion de documents scientifiques de niveau recherche, publiés ou non, émanant des établissements d'enseignement et de recherche français ou étrangers, des laboratoires publics ou privés. 


\section{Experimental characterisation of a plume above rectangular thermal sources. Effect of aspect ratio. \\ René DEVIENNE ${ }^{1}$, Jean Raymond FONTAINE ${ }^{2}$}

${ }^{1}$ LEMTA, CNRS UMR 7563

2, avenue de la Forêt de Haye, BP 160, 54504 Vandoeuvre-lès-Nancy Cedex, France

${ }^{2}$ Institut National de la Recherche et de la Sécurité, Département Ingénierie des Procédés, avenue de Bourgogne, BP 27, 54501 Vandeuvre-lès-Nancy Cedex, France

\section{Abstract}

An experimental study of the thermal plume emerging above a number of plane rectangular heat sources of finite dimensions was performed with the aim of verifying the corresponding point source or linear source models and the evolutions of the dynamic and thermal fields in relation to the aspect ratio. The heat sources were assembled from four rectangular units $1.5 \mathrm{~m}$ in length and $0.25 \mathrm{~m}$ in width. Four different configurations with aspect ratios between 1.5 and 6 were tested. Surface temperatures were chosen to maintain approximately the same convected power from the sources, for all the situations. A battery of sixteen anemometric probes and sixty four thermometric probes simultaneously recorded plume velocity and temperature distribution. These measurements allowed to determine the actual energy entrained by the plume above the source. Velocity measurements also allowed the plume flow rate to be evaluated. The evolution of $\Delta \mathrm{T}_{\mathrm{c}}$, the temperature difference between the maximum temperature and the ambient temperature for a given horizontal plane, yielded an approximation of the virtual origin that is in close agreement with the plume thermal and dynamic radii above the source. The values found for the flow rate and $\Delta T_{c}$ are compared with those predicted by linear or point source formulae in order to determine an aspect ratio limit.

Keywords: Plume, virtual origin, enthalpy, flow rate, rectangular heat source

1 Corresponding author. Tel.: +33-03-83-68-25-35.; fax: +33-03-83-68-25-32

E-mail : Rene.DEVIENNE@ensem.inpl-nancy.fr (R. Devienne).

\section{Nomenclature}

a,b half-axes for ellipses in the model (m)

$b_{D}, b_{T} \quad$ dynamic and thermal radii, for velocity and temperature difference values $\mathrm{w}_{\mathrm{C}} / \mathrm{e}$ and $\Delta \mathrm{T}_{\mathrm{C}} / \mathrm{e}(\mathrm{m})$ respectively

$C_{p} \quad$ specific heat capacity of air $\left(\mathrm{J} \cdot \mathrm{kg}^{-1} \cdot \mathrm{K}^{-1}\right)$ 


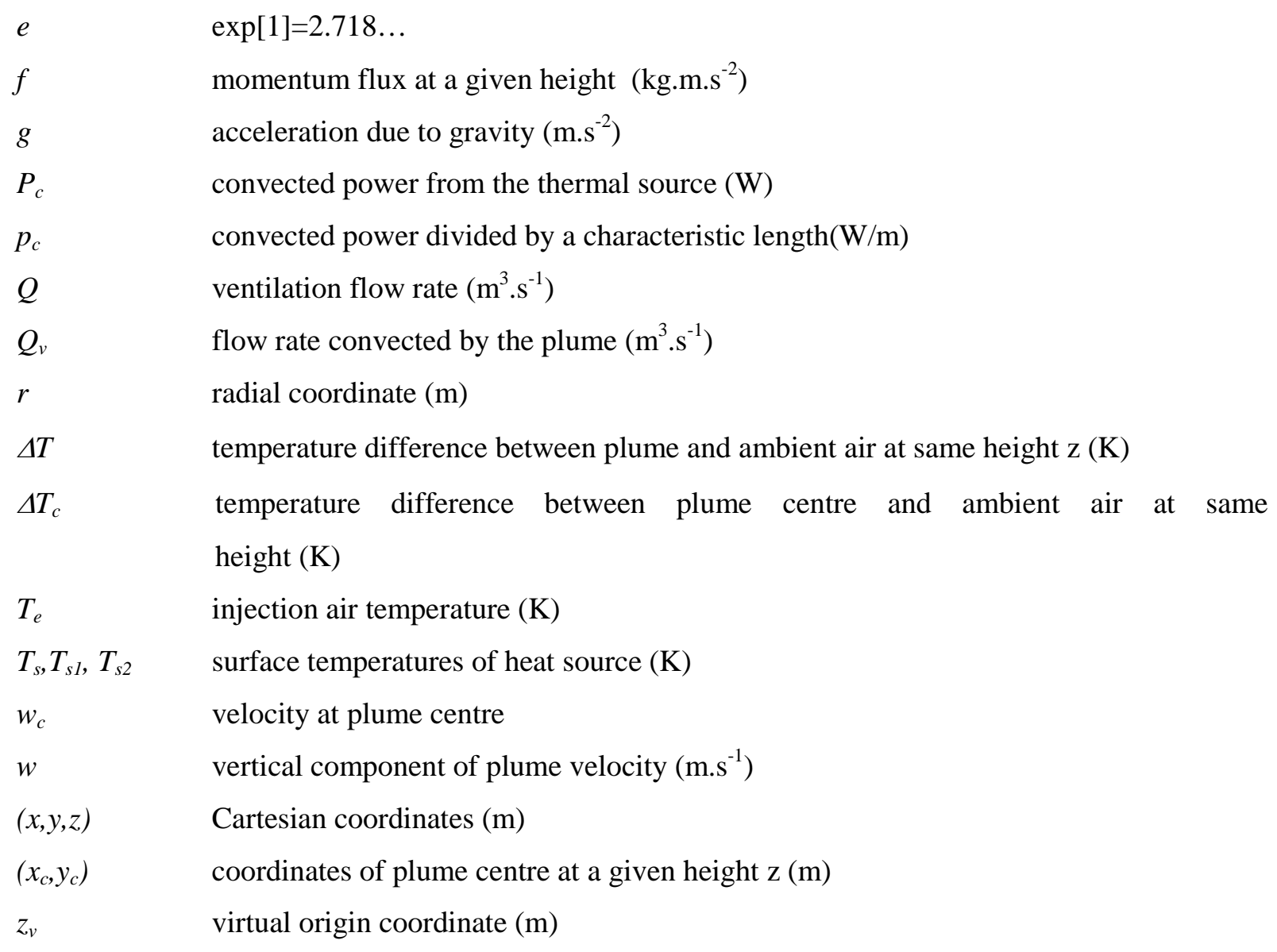

\section{Greek characters}

$\begin{array}{ll}\alpha & \text { entrainment coefficient for a plume } \\ \beta & \text { volume coefficient of thermal expansion }\left(\mathrm{K}^{-1}\right) \\ \lambda=b_{T} / b & \text { ratio of thermal radius } b_{T} \text { to dynamic radius } b \\ \rho_{\infty} & \text { density of surrounding space }\left(\mathrm{kg} \cdot \mathrm{m}^{-3}\right) \\ \Phi & \text { plume excess enthalpy at height } \mathrm{z}(\mathrm{W})\end{array}$

\section{Introduction}

Within a fluid with temperature-dependant density, any heat source will cause a plume to form as a result of natural convection. This plume will necessarily carry a flow rate by entrainment from the ambient fluid. These situations are of practical interest to industrial or geophysical environments since plumes convect thermal energy, but also sometimes pollutants of various types. Furthermore, energy recuperation and building ventilation fall within the scope of these studies.

The thermal sources encountered in industrial practice can be of very diverse natures: treatment tanks, molten metals, machine tools, and so on. For practical applications such as air purification, energy recuperation in workshops, the designers need to estimate parameters like flow rate, enlargement, maximum temperature of a plume. For this aim, two different 
families of predictive formulae are available that must be adapted to the proper situation. In addition, it is understandable that authors primarily focus on circular, cylindrical, linear sources for which some theoretical laws exist, and the academic approach can only give a general formulation. The basic results are given by results (1) to (5) to which corrections must be made like introducing a virtual origin and other corrections. Moreover, it should be borne in mind that it is possible to distinguish three zones in the spatial development of a plume, namely:

- a near zone,

- an intermediate zone,

- a zone termed the "established plume zone".

The first two zones depend on the geometric structure of the source and are the subject of work currently in progress as they remain relatively unknown; see Hunt and Kaye [1]. For the established zone it should be kept in mind that self-similar analytical solutions do exist concerning the plume generated by a punctual source; see the initial work of Morton et al. [2] The vertical component of the velocity field $w(\mathrm{x}, \mathrm{y}, \mathrm{z})$, it can be written as

$$
\begin{aligned}
& \mathrm{w}(\mathrm{x}, \mathrm{y}, \mathrm{z})=\mathrm{w}_{\mathrm{c}}(\mathrm{z}) \cdot \exp -(\mathrm{r} / \mathrm{b})^{2} \\
& \text { with } \mathrm{w}_{\mathrm{c}}(\mathrm{z})=\left[\frac{3 \cdot g \cdot \beta \cdot\left(\lambda^{2}+1\right)}{2 \cdot \pi \cdot \rho \cdot \mathrm{C}_{\mathrm{p}}}\right]^{1 / 3} \cdot\left[\frac{6 a}{5}\right]^{-2 / 3} \cdot \mathrm{Pc}^{1 / 3} \cdot \mathrm{z}^{-1 / 3}
\end{aligned}
$$

$\mathrm{w}_{\mathrm{c}}$ being the maximum of vertical velocity which can be observed in an horizontal plane. For the temperature difference $\Delta \mathrm{T}=\mathrm{T}-\mathrm{T}_{\mathrm{e}}$, it can be written

$$
\begin{aligned}
& \Delta \mathrm{T}(\mathrm{x}, \mathrm{y}, \mathrm{z})=\Delta \mathrm{T}_{\mathrm{c}}(\mathrm{z}) \cdot \exp -(\mathrm{r} /(\mathrm{b} \cdot \lambda))^{2} \\
& \Delta \mathrm{T}_{\mathrm{c}}(\mathrm{z})=\left[\frac{3 \cdot g \cdot \beta \cdot\left(\lambda^{2}+1\right)}{2 \cdot \pi \cdot \rho \cdot \alpha \cdot \mathrm{C}_{\mathrm{p}}}\right]^{2 / 3} \cdot\left[\frac{6 a}{5}\right]^{-4 / 3} \cdot \mathrm{Pc}^{2 / 3} \cdot \mathrm{z}^{-5 / 3}
\end{aligned}
$$

where $r=\left[x^{2}+y^{2}\right]^{1 / 2}$, $z$ being a coordinate counted vertically from the point source and $P_{c}$ the total power generated at the source and convected by the plume. A detailed review of these results can be found in Mundt [3].

For an infinite linear source, the self-similar solution takes the form

$$
\begin{aligned}
& w(x, y, z)=w_{c} \cdot \exp -(y / b)^{2} \\
& w_{C}=\left[\frac{g \cdot \beta \cdot \sqrt{\left(\lambda^{2}+1\right) / 2}}{\rho \cdot \alpha \cdot C_{p}}\right]^{1 / 3} \cdot\left(p_{c}\right)^{1 / 3}
\end{aligned}
$$

the horizontal y axis being perpendicular to the longitudinal direction of the source . For this situation, as the source has an infinite length, $\mathrm{p}_{\mathrm{c}}$ designates the power generated by a unit of length of the source, as in the above formulae which are reported in Bender [4] . 
This situation is more difficult to achieve experimentally; the solution of the first case is considered as being adaptable to any case, the plume evolving towards this asymptotic solution whatever the initial geometry of the source.

It must be noticed that more recently, Fanneløp and Webber [5] obtained some solutions for the initial problem which are not simply powers of $\mathrm{z}$. They consider the momentum flux $\mathrm{f}=\int \rho \cdot \mathrm{w}^{2}$.ds as being the basic variable which leads to an implicit formulation for $\mathrm{z}$ and $\mathrm{Q}_{\mathrm{v}}$. The virtual origin is defined as the point for which $f=0$. These solutions are especially interesting for the near and intermediate zones of a plume.

To take the finite dimensions of real sources into account, the analytical solutions available are usually adapted by a correction termed "virtual origin", a correction that consists in replacing temperature difference and flow rate expressions in the velocity, the coordinate $\mathrm{z}$ of the plane above the source by $z-z_{v}, z_{v}$ designating the coordinate of an equivalent virtual source. As stated above, the plume generated by a source of finite dimensions can be rather well described in the fully developed zone by one of the two analytical forms mentioned in formulae (1-6). The developed zone is believed to appear for heights $\mathrm{z}$ above the source larger than a few source diameters. However in typical industrial applications the source diameter is of the order of a few metres which means that the analytical formulae apply for heights larger than $5 \mathrm{~m}$., i.e well above the occupied zone. A few examples could be mentioned: galvanization baths with typical surfaces of $15 \times 2.5 \mathrm{~m}^{2}$, powder coating of hot surfaces $\left(3 \times 2 \mathrm{~m}^{2}\right)$, bending of barrels of $1 \mathrm{~m}$ diameter, etc. The design of ventilation systems (capture hoods or displacement ventilation systems, for instance) for premises with industrial heat source requires the characterization of the associated plumes in the intermediate zone. One of the objectives of this paper is typically to present an experimental method applicable to analyzing plumes generated by a finite rectangular source of variable aspect ratio (from 1.5 to 6) in the development zone. The modelling of our experimental results will be based on generalized Gaussian distributions which can lead to non axi-symmetric iso-curves in order to highlight the privileged directions relative to the sources (see below).

\section{Material and methods}

\subsection{The experimental chamber}

It must be noticed that the experimental installation, the dimensions of which were similar to the ones of an industrial plant, allowed to directly determine the temperature and velocity fields above the heat source, the dimensions of which were also of the same order than the ones in practical cases. Further details concerning the experimental facilities were given previously, see Devienne R. et al. [6], nevertheless the main characteristics of the installation are shown in Figure 1.The bottom of the test chamber was delimited by a perforated floor allowing the injection of a controlled air flow rate Q. The same flow rate was extracted from the upper part of the chamber. For the following tests these flow rates were fixed at $Q$ $=2000 \mathrm{~m}^{3} / \mathrm{h}$. As the installation was used to determine the temperature and velocity fields only, the system works as a closed loop circuit, an air conditioning unit insuring a constant inlet temperature $\mathrm{T}_{\mathrm{e}}=293 \mathrm{~K}$.

\subsection{The thermal sources}

For the experiments, a total of four heat sources were available. Figure 2 provides the description of one of these modules. The upper horizontal plane constituted the heating element and was thermally insulated from the rest of the structure, the main geometric 
characteristics being the length $\mathrm{L}=1.5 \mathrm{~m}$ and the width $\mathrm{l}=0.25 \mathrm{~m}$. This upper part was made of copper on which a nickel coating had been deposited to limit radiation effects. The heating material could provide an adjustable electric power. A Platinum probe measured the surface temperature $\mathrm{T}_{\mathrm{s}}$ which could be fixed by the operator.

\subsection{Associated metrology}

Temperature and velocity measurements within the plume were made using a battery of 64 thermocouples (K type) and 16 anemometric probes. All were mounted on a support which could be moved along the $\mathrm{x}, \mathrm{y}$ or $\mathrm{z}$ direction, see Figure 1 for the definition of axes.

\subsection{Description of the model developed}

Due to the quantity of experimental data, a mathematical approach had to be developed to extract the essential characteristics of the thermal and velocity fields. As the velocity and temperature profiles predicted by the theory actually appeared, the following modelling is proposed

$$
\begin{aligned}
& \mathrm{w}(\mathrm{x}, \mathrm{y}, \mathrm{z})=\mathrm{w}_{\mathrm{c}}(\mathrm{z}) \cdot \exp [-\mathrm{f}(\mathrm{x}, \mathrm{y})] \\
& \mathrm{T}(\mathrm{x}, \mathrm{y}, \mathrm{z})-\mathrm{T}_{\mathrm{a}}=\Delta \mathrm{T}(\mathrm{x}, \mathrm{y}, \mathrm{z})=\Delta \mathrm{T}_{\mathrm{c}}(\mathrm{z}) \exp [-\mathrm{f}(\mathrm{x}, \mathrm{y})]
\end{aligned}
$$

where

$$
f(x, y)=\left(x-x_{0}\right)^{2}\left(\frac{\cos ^{2} \theta}{b^{2}}+\frac{\sin ^{2} \theta}{a^{2}}\right)+\left(y-y_{0}\right)^{2}\left(\frac{\sin ^{2} \theta}{b^{2}}+\frac{\cos ^{2} \theta}{a^{2}}\right)+\left(x-x_{0}\right)\left(y-y_{0}\right) \sin 2 \theta\left(\frac{1}{b^{2}}-\frac{1}{a^{2}}\right)
$$

$\mathrm{x}, \mathrm{y}, \mathrm{z}$ designate the coordinates of a measurement point.

The parameters appearing in the equation of function $f$ are naturally dependent on the physical quantity modelled, namely velocity or temperature. According to this model, in a fixed $z$ coordinate plane, the isothermal lines are ellipses with a centre $\left(x_{0}, y_{0}\right)$ and half-axes $a$ and $b$ whose orientation is given by the angle $\theta$; the same applies to the iso-velocity lines. Anticipating the results to be be presented, the iso-velocity and isothermal ellipses possessing the same centre and same orientation, it could be interesting to put forward:

$$
\lambda_{\mathrm{a}}=\mathrm{a}_{\mathrm{T}} / \mathrm{a}_{\mathrm{D}} \quad \lambda_{\mathrm{b}}=\mathrm{b}_{\mathrm{T}} / \mathrm{b}_{\mathrm{D}}
$$

where index $\mathrm{T}$ corresponds to the thermal field and index $\mathrm{D}$ corresponds to the velocity field. It should be noted that these ratios can a priori be dependent on coordinate $z$ of the plane considered. Determination of the parameters entering into formula 8 is achieved by means of a numerical solver with a least squares type approach between estimate and measurement.

Clearly, many other possibilities for the function $\mathrm{f}$ can be proposed, especially when the fields are supposed to be asymmetrical, see Zukowska et al. [7] The model we propose is the simpler evolution between the two theoretical cases, with a minimal number of parameters. Certain magnitudes such as orientation $\theta$ can be set $a$ priori so as to reduce the number of degrees of freedom in the model. The proposed model has necessarily some limits, because the plume is supposed to exhibit some symmetry around a vertical axis. A numerical simulation developed in the laboratory showed that the thermal field may present two maximums for horizontal planes situated closely to the heat source but they are not very marked. Another limit is linked with the following. Then arises the question of estimating the uncertainty attached to the parameters stemming from the modelling. In the case of the 
temperature field, the process used requires expressing the seven partial derivatives relative to the parameters of the model, i.e. $\frac{\partial \mathrm{T}}{\partial \mathrm{T}_{\mathrm{e}}}, \frac{\partial \mathrm{T}}{\partial \Delta \mathrm{T}_{\mathrm{c}}}$, and so on, then calculating these magnitudes for each of the 64 measurement points. This therefore means drawing up a X(64 x 7) matrix, the confidence intervals being obtained by way of the diagonal elements of the matrix $[\mathrm{XX}]^{-1}$, see Press et al. [8] .

Error bars on Figure 3 correspond to this interpretation. Again, anticipating the experimental results obtained, Figure 3 gives an example of the thermal field approach, an approach in which the temperature variations along the $x$ and $y$ axes are represented.

\section{Experimental results}

The full set of experimental results can be found in the PhD thesis by Blaise J. [9]

Four characteristic configurations were retained for presentation, namely:

Case 1: source comprising only one heating element; aspect ratio $=$ length/width $=6$, surface temperature $=623 \mathrm{~K}$

Case 2: source comprising 2 heating elements; aspect ratio $=3$, surface temperature $=593 \mathrm{~K}$

Case 3: source comprising 3 heating elements; aspect ratio $=2$, surface temperature $=423 \mathrm{~K}$

Case 4: source comprising 4 heating elements; aspect ratio $=1.5$, surface temperature $=393 \mathrm{~K}$

In fact, the surface temperatures were limited by technical constraints linked to the construction of the sources as well as by the total electrical power that could be supplied by the installation. The aforementioned surface temperature values were chosen as a function of the criteria stated, but also to obtain total convected powers of the same order of magnitude. In fact, according to classical correlations, the powers for cases 1,3 and 4 were about half as that for case 2.

\subsection{Global characterization of velocity and temperature fields, expansion of the plume}

Figures $4 \mathrm{a}, \mathrm{b}, \mathrm{c}, \mathrm{d}$ present the sequence of isotherms corresponding to $\Delta \mathrm{T}=\Delta \mathrm{T}_{\mathrm{c}} / \mathrm{e}$, for horizontal planes with $1.25 \mathrm{~m}<\mathrm{z}<3.75 \mathrm{~m}$. Figure 4 a gives a spatial view of this isotherms. More explicitly, Figure $4 \mathrm{~b}$ is a projection of this isotherms on the horizontal plane $\mathrm{z}=0$, Figures $4 \mathrm{c}$ and $\mathrm{d}$ correspond to projections on planes $\mathrm{x}=0$ or $\mathrm{y}=0$ and show the evolution of $\mathrm{a}_{\mathrm{T}}$ and $\mathrm{b}_{\mathrm{T}}$ with the $\mathrm{z}$ coordinate (two heat sources), Figure 4e corresponds to the case of one heat source. It should be noted that for cases 1 and 2, these isotherms are made up of ellipses whose main axes are aligned with the longitudinal and transversal directions of the sources. These ellipses evolve towards a circular shape as the measurement plane goes up. The large half-axis $\mathrm{a}_{\mathrm{T}}$ varies only slightly in the domain tested, and small half-axis $\mathrm{b}_{\mathrm{T}}$ increases with $\mathrm{z}$.

For cases 3 and 4, the isotherms appear to be practically circular for the first measurement planes; see Figure $5 \mathrm{a}$,b.

A similar situation can observed for the velocity field. Figure $5 \mathrm{c}$ gives an example of the evolution of the iso-velocity lines with $\mathrm{z}$ (case 2. Note however that the evolution does not appear to be complete for the last measurement plane). Also is also noteworthy that the values of parameters $a_{D}$ and $b_{D}$, obtained for the characterization of the velocity field, are higher than those of the temperature field.

Since a and b parameters may evolve in different manners, we propose to test two distinct characteristic lengths corresponding to dynamic radii, b or $\sqrt{\mathrm{ab}}$. Figures $6 \mathrm{a}$ and $6 \mathrm{~b}$ illustrate the evolution of these quantities as a function of coordinate $\mathrm{z}$ : $\left(\mathrm{b}_{\mathrm{T}}\right.$ for Fig. $6 \mathrm{a}$ and $\sqrt{a_{D} b_{D}}$ for Fig.6b)

- cases 1 and $2: \mathrm{a} \approx$ constant 
- cases 3 and 4: a and b evolve in an identical way, with $\mathrm{a} / \mathrm{b} \approx 1$.

Due to limited precision on b values and also to a small number of points, the values observed are perfectly compatible with the formulae for the radius, i.e.:

$$
\begin{aligned}
& \mathrm{b}=\frac{5 \alpha}{6}\left(\mathrm{z}-\mathrm{z}_{\mathrm{v}}\right) \\
& \mathrm{b}=\frac{2 \alpha}{\sqrt{\pi}}\left(\mathrm{z}-\mathrm{z}_{\mathrm{v}}\right)
\end{aligned}
$$

additional results stemming from formulae 1 to 6 .

The corresponding values for the slopes being $0.12 \pm 0.02$ [Figure 6.a] and $0.11 \pm 0.02$ [Figure6.b]. These values are consistent with an entrainment coefficient like $0.78<\alpha<1.03$ values for which there is some consensus for the cylindrical or circular sources, see Kokofed and Nielsen [10]. The existence of a constant entrainment coefficient $\alpha$ is an hypothesis on which formulae 1 and 2 are based, an hypothesis that is still debated.

So, it appears that we cannot discriminate between the use of the two proposed formulation $b$ or $\sqrt{\mathrm{ab}}$.

\subsection{Energy convected by the plume}

When a problematic like air conditioning or energy recuperation is considered, the total energy extracted from the source and convected by the plume is necessarily one of the most important parameters. The excess of enthalpy is expressed as $\Phi(\mathrm{z})=\iint \rho \mathrm{C}_{\mathrm{p}}\left[\mathrm{T}-\mathrm{T}_{\mathrm{e}}\right] \cdot \mathrm{w}(\mathrm{x}, \mathrm{y}, \mathrm{z}) \cdot \mathrm{dx} \cdot \mathrm{dy}$. Insofar as the experimental results highlighted a coincidence for the central points $\left(x_{0}, y_{0}\right)$ and for the orientation $\theta$ for the modelling of the dynamic and thermal fields, the preceding result can be simplified to the form

$$
\Phi(\mathrm{z})=\rho \mathrm{C}_{\mathrm{p}} \sqrt{\frac{\lambda_{\mathrm{a}}^{2}}{\lambda_{\mathrm{a}}^{2}+1}} \cdot \sqrt{\frac{\lambda_{\mathrm{b}}^{2}}{\lambda_{\mathrm{b}}^{2}+1}} \Delta \mathrm{T}_{\mathrm{c}}(\mathrm{z}) \cdot \mathrm{w}_{\mathrm{c}}(\mathrm{z}) \cdot \pi \cdot \mathrm{a} \cdot \mathrm{b}
$$

Table I includes information concerning the entrained energies. A mean value of the magnitudes was used for the calculus of the following paragraph.

\subsection{Virtual origin correction, influence of the aspect ratio}

From the curves on Figures 6, it is possible in principle to determine the virtual origin $\mathrm{z}_{\mathrm{v}}$, but given the low value of slope and its relative error, the determination turns out not to be very precise in the present situation. Moreover, some of the first experimental planes may be still situated in the developing zone of the plume.

It appears that a more precise determination of $\mathrm{z}_{\mathrm{v}}$ can be obtained using the variations of $\Delta \mathrm{T}_{\mathrm{C}}$ with the $\mathrm{z}$ coordinate ( $\Delta \mathrm{T}_{\mathrm{c}}$ being the maximum temperature difference observed for a given horizontal plane). For all cases, it is possible to find a valuable approximation like $\Delta \mathrm{T}_{\mathrm{C}}(\mathrm{z})=\mathrm{C} \cdot\left(\mathrm{z}-\mathrm{Z}_{\mathrm{v}}\right)^{-\mathrm{n}}$ in the domain tested. An important remark is that the index $\mathrm{n}$ must be confined between the two extremes values $1<\mathrm{n}<5 / 3$. Another work indicates that this is not possible if points too close to the heat source are considered, see Devienne et al. [11] An example of this determination is given on Figure 7. The results obtained are the following ones $\mathrm{z}_{\mathrm{v}}=-0.9 \mathrm{~m}, \mathrm{n}=1.1, \mathrm{z}_{\mathrm{v}}=-1 \mathrm{~m}, \mathrm{n}=1.33, \mathrm{z}_{\mathrm{v}}=-1.2 \mathrm{~m}, \mathrm{n}=1.5, \mathrm{z}_{\mathrm{v}}=-1.4 \mathrm{~m}, \mathrm{n}=1.61$ for cases 1 to 4 . The estimates obtained for $-z_{v}$ appear to be realistic and are of an order of magnitude of one characteristic dimension of the source. 
The flow rate entrained by the plume is a fundamental characteristic necessary for sizing capture devices. Measuring the vertical velocity component and modelling the field allows the determination of the entrained flow rate at a fixed coordinate $z$ in accordance with the formula: $\mathrm{Q}_{\mathrm{v}}=\iint \mathrm{w}$.ds $=\pi \mathrm{abw}_{\mathrm{c}}$

According to Figure 8, the experimental points corresponding to cases 1 and 2 can be grouped into a single curve, provided that a quantity dependence $\left(\mathrm{Q}_{\mathrm{v}} / \mathrm{L}\right)\left(\mathrm{P}_{\mathrm{c}} / \mathrm{L}\right)^{-1 / 3}$ proportional to $\left(z-z_{v}\right)$ is chosen (which is not possible for cases 3 and 4), the characteristic length $L$ being taken as the length of one source module. This evolution corresponds to the case of a linear source.

For cases 3 and 4, the experimental points can be grouped into a single curve depending on the choice of a $\left(z-z_{v}\right)^{5 / 3}$ evolution of the quantity $Q_{v} \cdot P_{c}^{-1 / 3}$ This evolution corresponds to the case of a point source (Figure 9 ).

The theoretical models are also acceptable for determining the maximum velocity $\mathrm{w}_{\mathrm{c}}$, $\mathrm{a}$ function of coordinate $z$, see table II.

It should however be pointed out that:

-the variations in $\mathrm{w}_{\mathrm{c}}$ remain limited in our measurement interval.

-the calculated velocity is slightly overestimated in relation to the measured values. This difference can be explained by the fact that the theoretical model considers a plume free in an ambient medium at rest. In the case of our installation, external air is injected into the lower section of the test cell, the flow rate being set to a value higher than that of an estimate of the plume flow rate at outlet level, to avoid stratification. Even if the iso-velocity lines are evolving, the low or zero dependence of $\mathrm{w}_{\mathrm{c}}$ regarding coordinate $\mathrm{z}$ does not allow the valid establishment of a law of variation as a function of this coordinate.

\subsection{Influence of non-uniform temperatures.}

As each heating unit is controlled independently of the neighbouring ones, it is possible to test situations for which the surface temperatures are not equal. We have considered the following particular cases:

- three heating units $\mathrm{T}_{\mathrm{s} 1}=\mathrm{T}_{\mathrm{s} 2}=\mathrm{T}_{\mathrm{s} 3}=423 \mathrm{~K}, \mathrm{~T}_{\mathrm{s} 2}$ standing for the surface temperature of the middle element

- three heating units $\mathrm{T}_{\mathrm{s} 1}=\mathrm{T}_{\mathrm{s} 3}=423 \mathrm{~K}, \mathrm{~T}_{\mathrm{s} 2}=623 \mathrm{~K}$

- three heating units $\mathrm{T}_{\mathrm{s} 1}=\mathrm{T}_{\mathrm{s} 3}=358 \mathrm{~K}, \mathrm{~T}_{\mathrm{s} 2}=623 \mathrm{~K}$

- one heating unit $\mathrm{T}_{\mathrm{s}}=623 \mathrm{~K}$, that is to say the preceding case 1 .

On Figure 10, the quantity $\mathrm{Q}_{\mathrm{v}} / \mathrm{P}_{\mathrm{c}}{ }^{1 / 3}$ is compared to the one for the case 358-623-358 chosen as a reference case. As the height above the source is growing up, the influence of the real size of the source and that of the distibution of surface temperatures tend to disappear and the ratio go to 1 . The case $423-423-423$ is somewhat different from the other ones. This is more evident considering the quantity $\Delta \mathrm{T}_{\mathrm{C}} / \mathrm{P}_{\mathrm{c}}{ }^{1 / 3}$ which is reported on Figure 11 , this is also confirmed by $\mathrm{w}_{\mathrm{c}} / \mathrm{P}_{\mathrm{c}}^{1 / 3}$. From a practical point of view, it is possible to conclude that for the 3 last situations, the central zone of heating source impose a comportment similar to the one of a linear source, the first case 423-423-423 must be treated like a 'circular' source.

\section{Conclusion}

In this paper we developed experimental methods combined with plume data modelling to describe temperature and velocity distributions of the convective flow generated by a twodimensional rectangular heat source of variable aspect ratio in the development zone that is of 
major interest for industrial hygiene applications. Within the limits of the experimental parameters interval, isotherm or iso-velocity lines are close to ellipses, the principal directions of which coincide with the longitudinal and transversal directions of the sources. The evolution towards a circular shape relies on different evolutions of the a and b parameters with the height $\mathrm{z}$ above the source. Quantities like a or $\sqrt{\mathrm{a} . \mathrm{b}}$ exhibit a linear behaviour z but the experimental domain of the test is not sufficient to give a precise determination of the virtual origin $z_{v}$, this determination appear to be more accurate using the central temperature excess $\Delta \mathrm{T}_{\mathrm{c}}$ as a function of $\mathrm{z}$, with some limitations.

Concerning $Q_{v}$, the flow rate convected by the plume, it is possible to state the following : -for an aspect ratio greater than 2, a better approach is provided by considering the punctual heat source formulae.

- for an aspect ratio less than 2, the formulae corresponding to a linear source must be considered. This relies on the fact that the curves for $\mathrm{Q}_{\mathrm{v}} \cdot \mathrm{P}_{\mathrm{c}}^{-1 / 3}$ or $\frac{\mathrm{Q}_{\mathrm{v}}}{\mathrm{L}}\left(\mathrm{p}_{\mathrm{c}}\right)^{-1 / 3}$ may be grouped on two different lines. 


\section{References}

[1] Kaye $\mathrm{N}$ and Hunt $\mathrm{G}$ 'An experimental study of large area source turbulent plumes' Int. J of Heat and Fluid Flow, Vol. 30, Issue 6, pp1099-1105 (december2009)

[2] Morton BR, Taylor G and Turner JS (1956) 'Turbulent gravitational convection from maintained and instantaneous sources’. Pro R Soc Series A Math Phys Sci; 234: 1-23

[3] Mundt E ' The performance of displacement ventilation systems : experimental and theoretical studies’ Ph. D thesis KTH-Royal Institute of Technology, Stockholm (1996).

[4] Bender M (1979) 'Fume Hoods, open canopy types. Their ability to capture pollutants in various environments’ Am. Industrial Hygiene Assoc. J. 40, pp 118-127

[5] Fanneløp $\mathrm{T}$ and Webber $\mathrm{D}$ 'On buoyant plumes rising from area sources in a calm environment’ J. Fluid Mech. (2003) vol. 497 p 319-334

[6] Devienne R, Fontaine JR, Kicka J 'Experimental characterization of a plume of passive contaminant above a thermal source: capture efficiency of a fume extraction hood' Ann.Occup. Hyg October 2009 ; 53: 739-748

[7] Zukowska D, Popoliek Z Melikov 'A determination of the integral characteristics of an asymmetrical thermal plume from air speed/velocity and temperature measurements' Exp.Thermal and Fluid Science vol.34, issue 8(2010), p 1205-1216

[8] Press WH, Flannery BP, Teukolsky SA, Vetterling WT ' Numerical Recipes', ch 14 Modeling of data. Cambridge University Press (1989)

[9] Blaise, J ( 2008) 'Influence de la géométrie d'une source thermique sur le développement du panache', thèse de l'Université Henri Poincaré, Nancy, France http://petale.univlorraine.fr/index.html

[10] Kokofed P, Nielsen P 'Thermal plumes in ventilated rooms : measurement in stratified surroundings and analysis by use of an extrapolation method' Proc. Building Simulation'97, (1990), vol.1, 233-239

[11] Devienne R, J-R Fontaine and Maalej T 'Experimental characterization and numerical simulation of plumes above thermal sources. Transport of a passive contaminant' Proceedings of the $14^{\text {th }}$ International Heat Transfer Conference (IHTC14), August 8-13, 2010, Washington, DC, USA 


\section{Figure captions}

Fig. 1 General view of the experimental installation 1 Test zone 2 Perforated floor 3 Heat source 4 Inlet pipes 5 Air conditioning unit 6 Perforated ceiling 7 Outlet pipes

Fig. 2 Heat source

Fig. 3 Variations of the temperature difference $\Delta \mathrm{T}$ with $\mathrm{x}$ or $\mathrm{y}$ coordinate for a fixed value of the $\mathrm{z}$ coordinate

Fig. 4 Isotherms evolution with the height above the source a) $3 \mathrm{D}$ view of $\Delta \mathrm{T}_{\mathrm{C}} / \mathrm{e}$ isotherms b) Vertical projection on a $\mathrm{z}=0$ plane c) Projection on $\mathrm{x}=0$ plane d) Projection on $\mathrm{y}=0$ plane e) Case of one source

Fig. 5 Isotherms $\Delta \mathrm{T}_{\mathrm{c}} / \mathrm{e}$ or iso-velocity lines $\mathrm{w}_{\mathrm{C}} / \mathrm{e}$ evolution with the height above the source. a) Isotherms, 3 sources b) Isotherms, 4 sources c) Iso-velocity lines

Fig. 6 Variations of the $b_{\mathrm{T}}$ or $b_{\mathrm{D}}$ parameters with the $\mathrm{z}$ coordinate

Fig. 7 The central temperature difference $\Delta$ Tc as a function of $\mathbf{z}-z_{\mathrm{v}}$

Fig. 8 Reduced flow rate $\left(\mathrm{Q}_{\mathrm{v}} / \mathrm{L}\right) /\left(\mathrm{P}_{\mathrm{C}} / \mathrm{L}\right)^{-1 / 3}$ versus $\mathrm{z}-\mathrm{Z}_{\mathrm{v}}$

Fig. 9 Reduced flow rate $\mathrm{Q}_{\mathrm{v}} 3^{15} / \mathrm{P}_{\mathrm{c}}^{-1 / 5}$ versus $\mathrm{z}-\mathrm{Z}_{\mathrm{v}}$

Fig. 10 Flow rate comparison for non uniform surface temperatures

Fig. 11 Temperature difference comparison for non uniform surface temperatures 